\title{
Creation of Formula to Predict Time and Cost Benefit by Using 5D BIM Rather than Traditional Method of Construction
}

\author{
Arif Khan $^{1 *}$ and Ayesha Muneeb ${ }^{2}$ \\ Architectural Engineering and Design, Pakistan \\ *Corresponding author: Arif khan, Architectural Engineering and Design, Pakistan
}

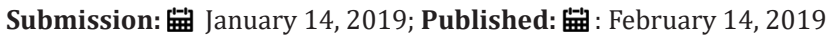

\begin{abstract}
Building Information Modeling (BIM) is becoming a well-known established collaboration process in the construction industry. Owners are increasingly requiring BIM services from construction managers, architects and engineering firms. Many international construction firms are now investing in "BIM" technologies during bidding, preconstruction, construction and post construction. The goal of this research is to understand and examine the uses and benefits of 5D BIM for construction project of Pakistan. There are three objectives to this research. First is to make comparative analysis of an existing high rise building with reference to scheduling and cost as done by traditional method. Second is to develop 5D model of high rise building with help of autodesk revit and autodesk navisworks. Third is to make 3D models of 20 and 30 storey building on autodesk revit and navisworks by making 10 storey building as reference to overview the comparative benefits of schedule and cost with help of 5D BIM and development of formula with reference to schedule and cost for any number of stories of building. First an existing commercial building was selected for comparative study between 5D BIM analysis and traditional CAD methods. 5D Building information model was created and analyzed. Furthermore, the BIM-based schedule and cost was integrated to 5D model. Finally, the project concluded with an analysis on the advantages of 5D BIM and its implementation barriers in construction industry of Pakistan. The study concludes that despite of few shortcomings and barriers in 5D BIM implementation, BIM and 5D construction processes are concluded as a promising tool for construction planning. 5D BIM modeling helps to reduce time and cost of a project and provide efficient planning by better visualization of construction work, better communication among project teams, detailed and accurate work plans and quantity takeoffs. Also, with increase in number of stories time and cost benefits also increase in 5D BIM.
\end{abstract}

Keywords: Building information modeling (BIM); Work breakdown structures (WBS); Percentage plan complete (PPC)

\section{Introduction}

The Construction industry has a greater impact on the economy of all countries. It is one of the sectors that provide crucial ingredients for the development of economy. Due to poor cost and time management these days, the construction industry is facing a huge amount of cost overrun. This has become quite a problem for the construction industry. Poor cost management and overrun are huge problem and very serious issue when it comes to project cost in both developed and emerging countries. The increasing complexity of infrastructure projects and the environment within which they are constructed place greater demand on construction managers to deliver projects on time, within the planned budget and with high quality [1].

There is still a great difference between execution and plan despite the fact that a huge number of planning methodologies have been adopted and implemented. But these are not enough to improve the construction process. Hence an competent and operative planning method is needed to increase project performance at different levels of project to minimize the risks of cost overruns and time delays [2]. The adoption of BIM for complex high-rise buildings gives innovative structure engineering and improved construction technology. Among such innovative engineering and technologies, structural analysis in construction process, automated clash detecting technology, real time construction sequence simulation and 3D measurement technology is obtained. Also, sophistication of collaboration environment, promotion of technology and construction innovation is obtained by implementing BIM to high rise buildings [3].

\section{Project cost management}

In order to succeed in managing a project, the project manager needs to learn how to make cost calculations, estimate resources required for the project, develop cost spreadsheets, use cost management templates, and more. The manager should understand that all information on the need, availability and consumption and of project resources (like labor, money, time, technology) can be gathered, filtered, sorted and managed by project cost management and its special methods. Let's find out what the process of managing project expenses means and what basic software functionality is necessary for performing the process. Project cost management is 
a series of activities for estimating, allocating, and controlling costs within the project. It allows determining and approving budget for the project and controlling spending. For example, in construction project cost management it is vital to estimate cost of materials, equipment, salary of workers, etc. In IT project cost management, it is critical to estimate cost of software development, salary of IT staff, etc. Effective project cost management allows each project to be specific and unique because that project entails costs and requires specific funding. However, no matter whether you lead a software development project (IT project cost management) or construction project (construction project cost management), you should consider project cost management as a process that consists of the three key steps (get more info at the PM guidelines).

\section{Traditional project cost estimation processes}

The process of managing project costs is an activity for estimating costs, developing project budget and controlling spending. The project cost management process includes the following key steps:

Resource planning: In the initial phase of a project the required resources to complete the project activities need to be defined. Work Breakdown Structures (WBS) and historical information of comparable projects can be used to define which physical resources are needed. You can think of the required time, material, labor, equipment, etc. Once the resource types and quantities are known the associated costs can be determined.

Cost estimation: It is the project cost management process step when the project manager cooperates with the financial department to estimate costs required for purchasing all necessary good/services and undertaking necessary activities to deliver the project. Project Cost Estimation is conducted at the planning phase. The project manager uses project cost management software to develop spreadsheets and make calculations.

Budget determination: At this step of the cost management process, cost spreadsheets are used to develop the budget framework and determine the budget. The project manager can use project cost management software to work in collaboration with the financial department to determine items of the budget and sources of funding and then to allocate the budget. The step entails close cooperation with the project sponsor.

Spending control: It is the step of the project cost management process when the allocated budget is reviewed, and spending is tracked. The project manager takes responsibility for control spending and to ensure that the budget allocation is optimized, and costs are fully covered with the planned and allocated budget.

\section{Limits of traditional approaches when planning resource and cost in complex projects}

Ambiguity: First, the resource allocation process is even more complex when information about the required skills or the skills possessed by potential project team members are unclear or ambiguous. Moreover, role conflict and role ambiguity have a direct influence on the creativity of a project team. When project team members face unclear or ambiguous specifications of what they are meant to do, this makes it all he more difficult to execute and coordinate the project.

Uncertainty: The inherent uncertainty of cost estimates makes it all the more difficult to establish a robust project cost baseline. Even though some advanced methods try to build up cost envelopes for each part of a single project, they remain not widely used by industrial practitioners.

Propagation: In terms of resource allocation, "a resource is a relative concept, rather than an element in itself because it is heterogeneous and interdependent with other resources it is combined with" Limits of Traditional Project Management Approaches. Resource allocation approaches, however, do not generally use this interdependence as a parameter, which may not facilitate resource coordination in the end. Moreover, to the best of our knowledge, there is no reputed approach which directly introduces the interconnection of activities in terms of cost and the potential propagation and consequences of a possible overcost during the execution of the project. One could however anticipate more the possibilities of cost reduction of other activities if a specific activity faces overcost. An interesting research perspective would be to facilitate the anticipation of cost monitoring and control through the introduction of possible cost decisions due to the complexity of the project networks [4].

\section{Project cost management with 5D BIM}

Building information modelling (BIM) provides both opportunities and challenges for the project cost management profession. As quantification increasingly becomes automated and BIM models develop the role of the project cost manager will need to adapt accordingly to provide more sophisticated cost management services that incorporate 4D time and 5D cost modelling and sharing cost information/data with the project team as part of the BIM integrated project delivery approach. The RICS (2014) contend that BIM provides project cost managers with the opportunity to spend more time on providing knowledge and expertise intensive advice to the project team-the automation of processes such as quantification will substantially reduce time spent on technical processes and will provide more time and the digital tools for higher value-added and more sophisticated cost management services. Mitchell (2012) describes the importance for the project cost management professional to embrace the 5th dimension and become key players in the BIM environmentthe '5D Project Cost Manager'. Muzvimwe (2011) supports this notion and describes the value of the cost manager in being able to simulate and explore various design and construction scenarios for the client in real time through having their cost data and quantities integrally linked in the live BIM model. This certainly raises the value of the cost management service but is dependent on the cost manager having BIM capability/expertise, sharing their cost data in the model and having the experience, expertise and intuition to analyze and critique the information that is being generated by the model [5]. 


\section{D BIM Tools}

\section{Autodesk Revit}

After introducing the most popular building information modeling software and autodesk as company that develops Revit, the spotlight will move now to Revit itself. In 1997 Reonid Raiz and Irwin Jungreis founded the company Charles River Software, which started building Revit. Their main goal was to include parametric modelling to existing idea of $\mathrm{CAD}$, and to allow the user to determine the parametric components graphically, instead of having to use a programming language. This idea of bidirectional associativity is the concept that distinguished Revit from other Building information modeling software platforms for a certain period of time, until the competition caught up. Bidirectional associativity means that when $u$ change a certain component of your model (for example wall) all components in relation with the modified one will automatically adjust themselves to applied changes. This concept of bi-directional associativity makes the software more intuitive and therefore easier to work with for the user. It also saves enormous amount of time when applying changes to an existing model.

\section{Microsoft project}

Using this software, we can get the actual cash flow, planned cash flow and achieved cash flow. Microsoft project is a project management software program, developed and sold by Microsoft, which is designed to assist a project manager in developing a plan, assigning resources to tasks, tracking progress, managing the budget, and analyzing workloads. Project creates budgets based on assignment work and resource rates. As resources are assigned to tasks and assignment work estimated, the program calculates the cost, equal to the work times the rate, which rolls up to the task level and then to any summary tasks and finally to the project level. Resource includes people, equipment and materials can be shared between projects using a shared resource pool. Each resource can have its own calendar, which defines what days and shifts a resource is available. Resource rates are used to calculate resource assignment costs which are rolled up and summarized at the resource level. Each resource can be assigned to multiple tasks in multiple plans and each task can be assigned multiple resources, and the application schedules task work based on the resource availability as defined in the resource calendars.

\section{Autodesk naviswork}

Autodesk navisworks manage is a software application providing a comprehensive project review solution which supports coordination, analysis, and communication of design intent and constructability. It allows integration of multidisciplinary design data created in different BIM design applications to a single project model. It also provides the interference management and clash detection functions to anticipate and avoid potential problems in the project which can eventually minimize delays and reworks. In addition, it supports 4D and 5D simulation and analysis by combining parametric models with the project schedule and costs.

\section{D Bim Implementation Studies}

\section{Case study 1}

5D BIM analysis on an existing local project

Introduction- b-type apartment building, sector i-16/3 islamabad: An existing small-scale commercial building was selected to illustrate the process of visualization, scheduling and cost estimation in BIM. The building selected for this purpose was "B-type apartments sector I-16/3 ISLAMABAD “. This was selected because it has simple architectural and structural designs, data was easily available, relevant to research, and traditional tools were used for designing and construction process. Figure 1 shows the perspective view of building (Table 1). The building is basically a framed structure residential flats building having two staircases and two lifts. The estimated project duration was calculated to be 2.6 years, but it actually got completed in 3.5 years. Total project cost was estimated to be $175 \mathrm{M}$, but its actual cost was about $218 \mathrm{M}$.

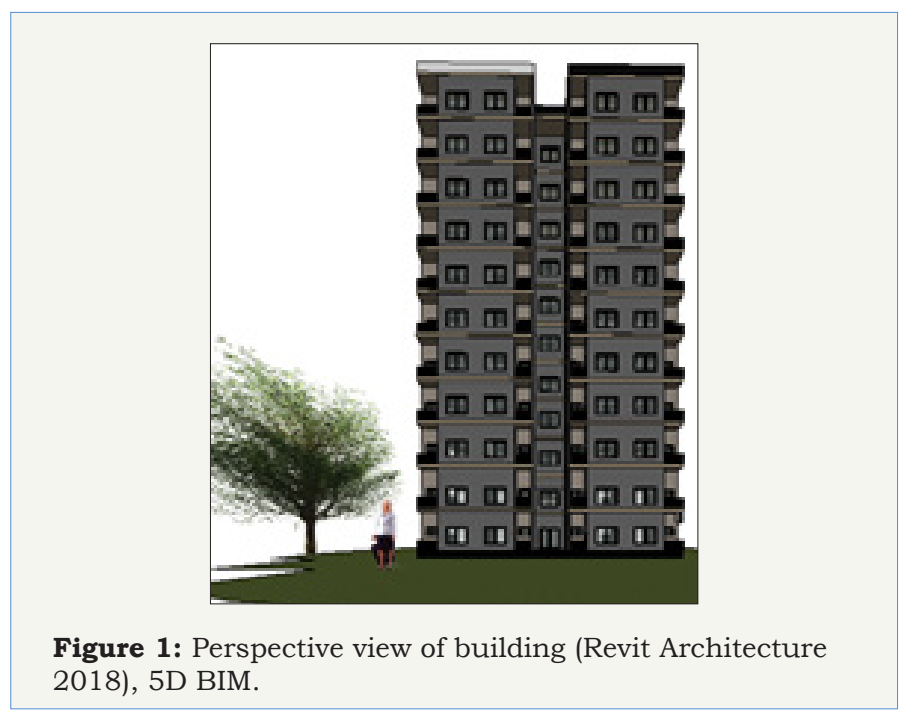

Table 1:

\begin{tabular}{|c|c|}
\hline Client & PHA Foundation, Islamabad. \\
\hline Consultant & Sampak International (Pvt.) Ltd, Lahore. \\
\hline
\end{tabular}

Traditional tools-design and construction process: The traditional tools used for the design and construction process of this building are described below. These tools are commonly used traditional tools in the construction industry of Pakistan.

A. Design Works-AutoCAD and Sketchup

B. Project Scheduling-MS Project

C. Quantities and Cost Estimation-Microsoft Excel

Time analysis of b-type apartment building: On the basis of data collected, time analysis on B-Type apartment building was performed. The graphical representation of analysis is shown below in Figure 2. The blue bar shows the planned duration of the project and orange bar shows the actual duration of project. The estimated project duration was calculated to be 2.6 years but it 
actually got completed in 3.2 years. The major difference in actual and planned duration of the project occurs during the construction phase i.e. $83 \%$. The construction phase was planned to be complete in 2 years, but it got completed actually in 2.6 years. In construction phase it can also be seen that major difference occurs in civil works i.e. $80 \%$. Whereas design phase duration contains $9 \%$ difference of actual and estimated project time. According to lean construction institute, a well-managed project has PPC (percentage plan complete) value greater than $60 \%$. It is the ratio between actual and estimated project duration. B-Type apartment building project has a PPC value calculated as $12 \%$ which shows it was a poorly managed project.

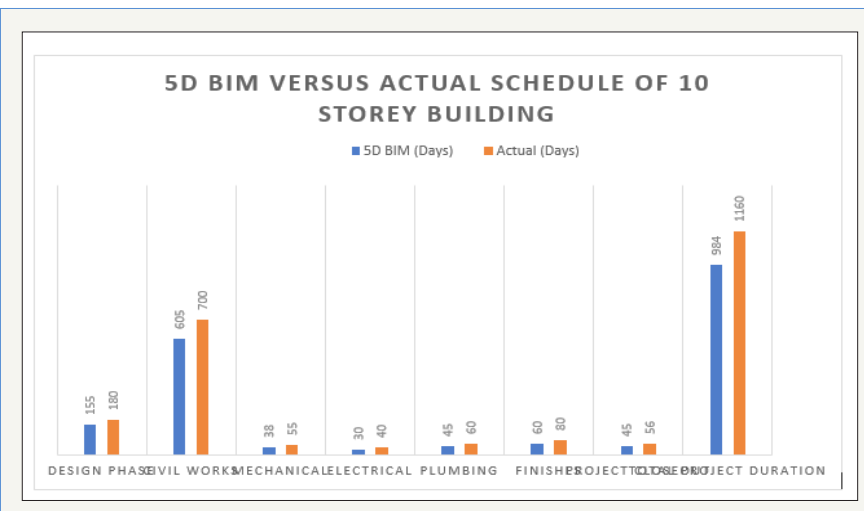

Figure 2: Project time analysis-b-type flat building.

Cost analysis of $\mathbf{b}$-type apartment building: It is observed during project time analysis of B-Type apartment building, the major difference of time occurred during the construction phase of the project. Therefore, cost analysis of project during construction phase was conducted. The cost analysis is shown in Figure 3. The bar in blue shows planned or 5D BIM cost and bar in orange shows the estimated cost. Total project cost was estimated to be $175 \mathrm{M}$, but its actual cost was about $218 \mathrm{M}$. It means $42 \mathrm{M}$ is the difference in estimated and actual cost of the project. So major increase in cost was occurred in structure, finishes and electrical works. The estimated cost of structure work was $138 \mathrm{M}$ while its actual cost came out to be $168 \mathrm{M}$.

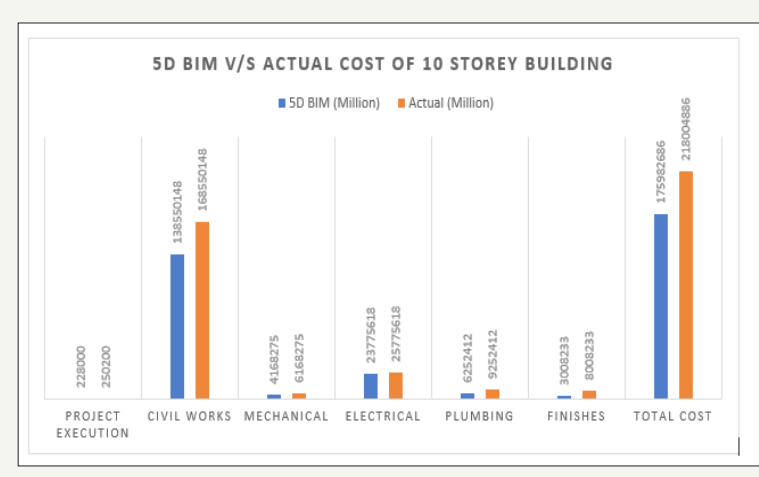

Figure 3: Project cost analysis - b-type apartment building.

\section{Case Study 2}

5d Bim Analysis on A 20 And 30-Storey Building with Reference To 10-Storey Building
Introduction-analysis on 20 storey building: A 5D BIM model of 20 storey building was created by taking the case study one's 10 storey apartment building as reference and making these assumptions that 20 storey building has:

a. Same storey height as of 10 storey building.

b. Same building area as of 10 storey building.

c. Same type of unexpected time and cost overruns occur as of 10 storey building.

Time analysis of 20 storey building: On the basis of data collected from analysis of ten storey B-Type Apartment Building, time analysis on 20 storey building was performed by taking ten storey building as reference. The graphical representation of analysis is shown below in Figure 4. The blue bar shows the planned duration of the project and orange bar shows the actual duration of project. The estimated project duration was calculated to be 3.4 years, but it actually got completed in 4 years. The major difference in actual and planned duration of the project occurs during the construction phase i.e. $80 \%$. The construction phase was planned to be complete in 2.7 years, but it got completed actually in 3.3 years. In construction phase it can also be seen that major difference occurs in civil works i.e. 84\%. Whereas design phase duration contains $11 \%$ difference of actual and estimated project time. According to lean construction institute, a well-managed project has PPC (percentage plan complete) value greater than $60 \%$. It is the ratio between actual and estimated project duration. B-Type apartment building project has a PPC value calculated as $12 \%$ which shows it was a poorly managed project.

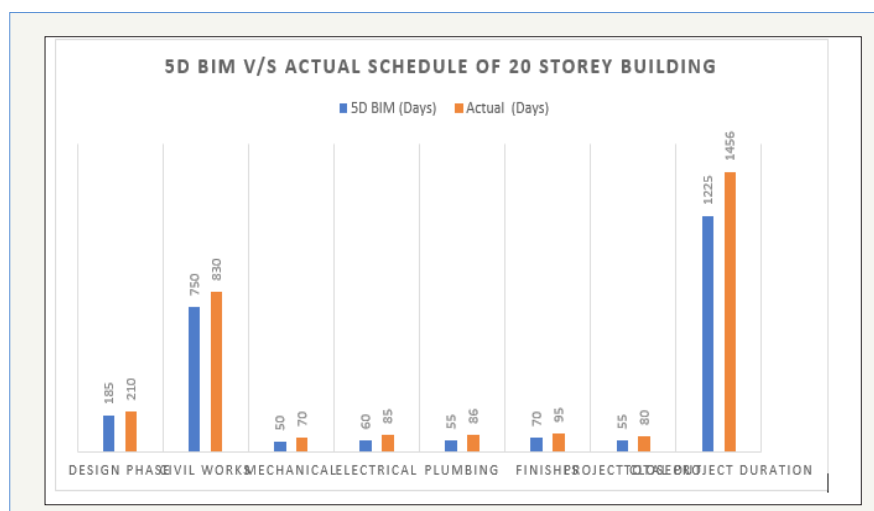

Figure 4: Project time analysis of 20 storey flat building.

Cost analysis of 20 storey building: It is observed during project time analysis of 20 Storey Building, the major difference of time occurred during the construction phase of the project. Therefore, cost analysis of project during construction phase was conducted. The cost analysis is shown in Figure 5. The bar in blue shows planned or 5D BIM cost and bar in orange shows the estimated cost. Total project cost was estimated to be $419 \mathrm{M}$, but its actual cost was about $521 \mathrm{M}$. It means $102 \mathrm{M}$ is the difference in estimated and actual cost of the project. So major increase in cost was occurred in structure, finishes and electrical works. The estimated cost of structure work was $331 \mathrm{M}$ while its actual cost came out to be $390 \mathrm{M}$. 
5D BIM V/S ACTUAL COST OF 20 STOREY BUILDING - 50 BIM (Million) - Actual (Million)

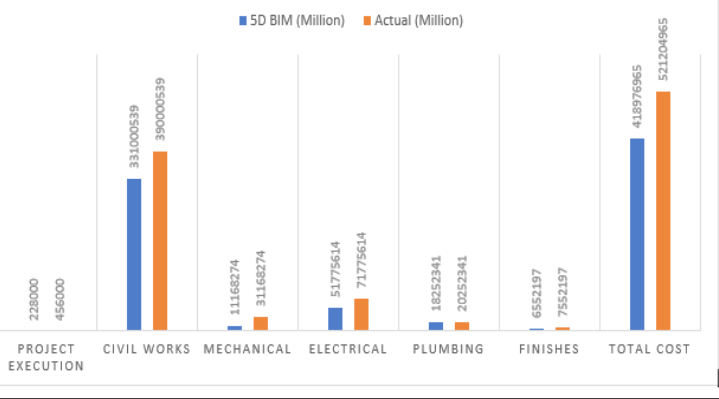

Figure 5: Project cost analysis of 20 storey apartment building.

\section{Introduction-analysis on 30 storey building}

A 5D BIM model of 30 storey building was created by taking the case study one's 10 storey apartment building as reference and making these assumptions that 30 storey building has:

A. Same storey height as of 10 storey building.

B. Same building area as of 10 storey building.

C. Same type of unexpected time and cost overruns occur as of 10 storey building.

5D BIM V/S ACTUAL SCHEDULE OF 30 STOREY BUILDING

$$
\text { -5D BIM (Days) =Actual (Days) }
$$

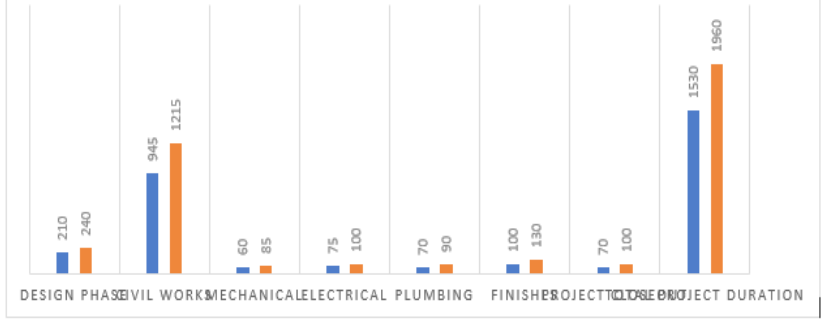

Figure 6: Project time analysis of 30 storey flat building.

Time analysis of $\mathbf{3 0}$ storey building: On the basis of data collected from analysis of ten storey B-Type apartment building, time analysis on 30 storey building was performed by taking ten storey building as reference. The graphical representation of analysis is shown below in Figure 6. The blue bar shows the planned duration of the project and orange bar shows the actual duration of project. The estimated project duration was calculated to be 4.1years but it actually got completed in 5 years. The major difference in actual and planned duration of the project occurs during the construction phase i.e. 85\%. The construction phase was planned to be complete in 3.4 years but it got completed actually in 4.2 years. In construction phase it can also be seen that major difference occurs in civil works i.e. $82 \%$. Whereas design phase duration contains $11 \%$ difference of actual and estimated project time. According to lean construction institute, a well-managed project has PPC (percentage plan complete) value greater than $60 \%$. It is the ratio between actual and estimated project duration.
B-Type apartment building project has a PPC value calculated as $12 \%$ which shows it was a poorly managed project.

Cost Analysis of 30 Storey Building: It is observed during project time analysis of 30 Storey Building, the major difference of time occurred during the construction phase of the project. Therefore, cost analysis of project during construction phase was conducted. The cost analysis is shown in Figure 7. The bar in blue shows planned or 5D BIM cost and bar in orange shows the estimated cost. Total project cost was estimated to be $706 \mathrm{M}$, but its actual cost was about $890 \mathrm{M}$. It means $184 \mathrm{M}$ is the difference in estimated and actual cost of the project. So major increase in cost was occurred in structure, finishes and electrical works. The estimated cost of structure work was $582 \mathrm{M}$ while its actual cost came out to be $702 \mathrm{M}$.

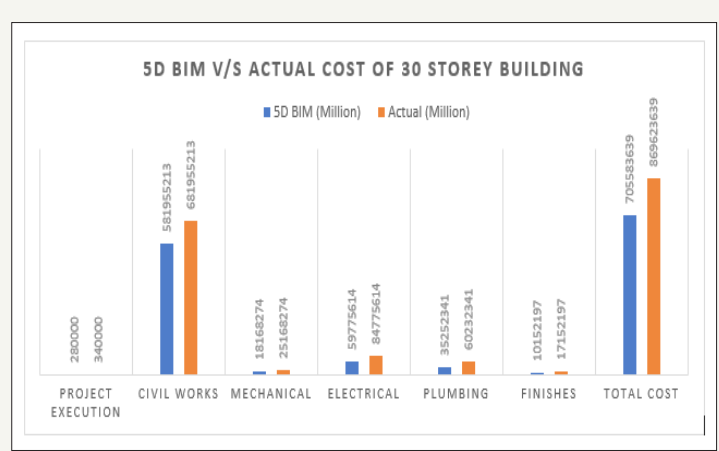

Figure 7: Project cost analysis of 30 storey apartment building.

\section{Results and Recommendation}

In this section, the results extracted from case studies will be discussed.

\section{Result from case studies}

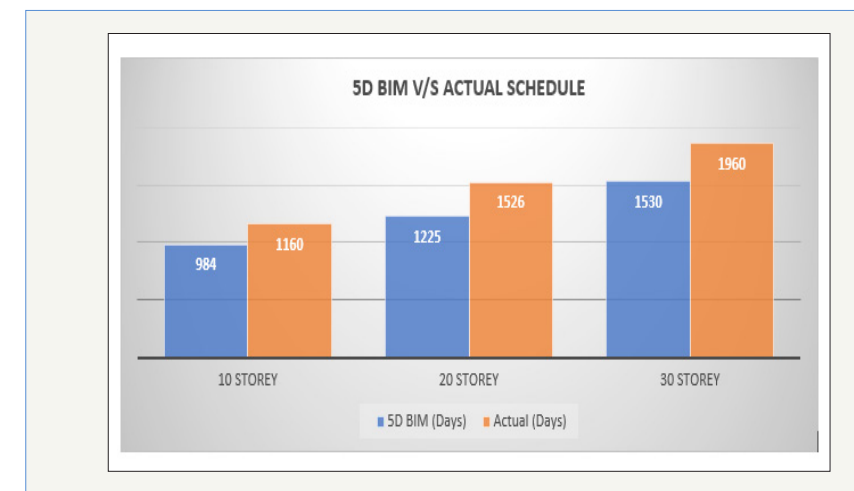

Figure 8: 5D BIM V/S Actual schedule comparison result.

On the basis of 5D BIM analysis of B-Type apartment building with building design from traditional method and by making it reference doing 5D BIM analysis of 20 and 30 storey building, time analysis was conducted. As shown in Figure 8, time in days are mentioned along y axis and storeys are mentioned along $\mathrm{x}$ axis. It can be clearly seen that by the use of 5D BIM technology, the project could have been completed as per the estimated time or even less if worked as per plan. The difference in planned and actual duration 
could have been reduced using 5D BIM. On the basis of 5D BIM analysis of ten, twenty and thirty storey building, cost analysis was evaluated. As shown in Figure 9, cost in millions are mentioned along y axis and building stories are mentioned along $\mathrm{x}$ axis. It can be observed that by the use of 5D BIM technology, the project could have been completed as per the estimated cost or even less if worked as per the plan. The difference in planned and actual cost could have been reduced using 5D BIM.

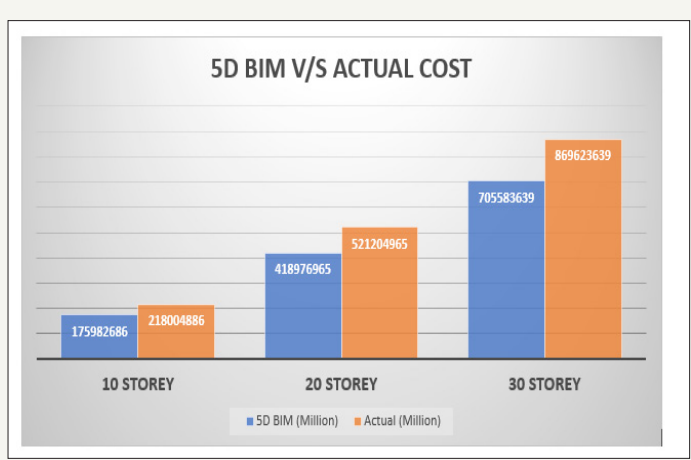

Figure 9: 5D BIM V/S Actual Cost comparison result.

On the basis of 5D BIM analysis of ten, twenty and thirty storey building, analysis of civil works is done. As shown in Figure 10, cost in millions are mentioned along y axis and building stories are mentioned along $\mathrm{x}$ axis. It can be observed that by the use of 5D BIM technology, the major factor of cost overrun is civil works. The difference in planned and actual cost could have been reduced using 5D BIM. Also, with increase in storey height more benefit in cost is achieved like in case of 30 storey building $120 \mathrm{M}$ can be saved if $5 \mathrm{D}$ BIM is used rather than traditional method of construction. As compared to traditional CAD method, BIM based detailed project design documentation can improve the visualization of the project, so design changes are reduced during construction phase. Quantity take-off and cost estimation taken by BIM is faster and more accurate as compared to traditional methods. When plans are created elevations, sections and even schedules are created automatically. So, time is not wasted on drafting and there are less chances of errors.

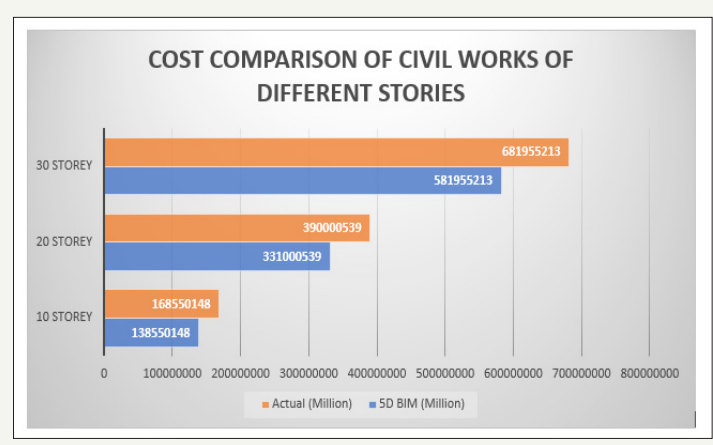

Figure 10: Cost comparison result of civil works of different stories.

An insight review of these case studies clearly shows that 5D BIM has brought many advanced construction management skills to project scheduling and cost estimation and also project controls for contractors. Since the quantities of building components are read by Autodesk Revit Architecture from BIM model directly. This will save contractors substantial amount of time on cost estimating. Also, the changes in design of building model can be updated in minutes in quantity take-off. It means that owner can get a faster cost feedback on changes in design using 5D BIM. In these case studies, the tasks defined with planned and actual dates in Gantt chart view. By comparison of planned and actual dates, the status bars can tell the contactor the progress of project in a simple way. The model of the progress can also help contractor to adjust the project schedule according to design change in building model.

With the help of 5D BIM, fresh engineer with less experience of management of project can produce a well-managed project. Knowledge and visualization are basic components of project management. An experienced project manager based on his experience can visualize 2D CAD drawings and can manage the project. But visualization of 5D BIM can enable fresh engineer to manage a project effectively. Construction of high-rise building projects can be managed well at fast tracks by planning and visualizing multiple tasking at pre-construction phase of project using 5D BIM. Better visualization of various construction process can help to improve the process of planning and improve the project team collaboration. If each and every project team member will be able to understand the design and construction process of the project, then collaboration among themselves will be increased.

\section{Creation of formulas for estimation of time and cost of various storey heights}

Formula of cost for $\mathbf{N}$ number of heights of building: As result of total cost estimation of 10, 20 and 30 storey building a comparison of their total costs is done. By comparing the difference in estimated and 5D BIM cost of ten, twenty and thirty storey building, a common value in their differences is obtained by making 10 storey building as reference (Table 2). By using this formula of number of storey, cost benefit of any number of storey can be done if it is built on 5D BIM rather than traditional method. For example, if any owner wants to build 100 storey building by 5D BIM and he/she wants to know overall cost benefit, it can be seen easily by putting number of storey as 100 in above formula.

Table 2: Cost benefit of $(100$ no of storey $)$ by $5 \mathrm{D}$ BIM $=\frac{(42 \mathrm{M} \times 100)+((100-10) \times 20 \mathrm{M})}{10}$

\begin{tabular}{|c|c|c|c|}
\hline Number of stories & 5D BIM & Actual & Difference \\
\hline 10 Storey & 175982686 & 218004886 & 42022200 \\
\hline 20 Storey & 418976965 & 521204965 & 102228000 \\
\hline 30 Storey & 705583639 & 869623639 & 164040000 \\
\hline
\end{tabular}

$\mathrm{N}=$ Number of total stories $=100$

Cost benefit of (100 no of storey) by 5D BIM $=600 \mathrm{M}$

From the above formula it can also be said that with increase in stories of a building, cost benefit also increases. More the number of stories more are the losses in cost that can be avoided. 
Formula of schedule for $\mathrm{N}$ number of heights of building: Similar procedure can be done in case of schedule of a building by making ten storey building as a reference and taking differences between actual and 5D BIM schedule. By comparing the values of differences of ten, twenty and thirty storey building a formula is devised that can tell what benefit in form of days is obtained if $5 \mathrm{D}$ BIM is used rather than traditional method (Table 3). By using this formula of number of storey, schedule benefit of any number of storey can be done if it is built on 5D BIM rather than traditional method. For example, if any owner wants to build 100 storey building by 5D BIM and he/she wants to know overall schedule benefit, it can be seen easily by putting number of storey as 100 in above formula.

Table 3:

Schedule benefit of $(100$ no of storey $)$ by $5 \mathrm{D}$ BIM $=\frac{(176 \text { Days } \times 10)+((100-10) \times 120 \text { Days })}{10}$

\begin{tabular}{|c|c|c|c|}
\hline Number of stories & 5D BIM & Actual & Difference \\
\hline 10 Storey & 984 & 1160 & 176 \\
\hline 20 Storey & 1225 & 1526 & 301 \\
\hline 30 Storey & 1530 & 1950 & 420 \\
\hline
\end{tabular}

$\mathrm{N}=$ Number of total stories $=100$

Schedule benefit of (100 no of storey) by 5D BIM = 1098 Days

\section{Conclusion and Recommendation}

\section{Conclusion}

With the help of analysis of time and cost of ten, twenty and thirty storey building by traditional and 5D BIM method. It can be seen that with increase in storey height due to increase in complexity of projects time delays and cost overruns are very common. Also, in civil works both these delays have their major part. With help of 5D BIM it is seen that time and cost benefits are obtained and with increase in storey height these benefits in terms of days and cost also increases.

By the assistance formula devised to see the $5 \mathrm{D}$ benefits in terms of time and cost. By only putting storey height in the formula one can easily find out that how much saving in terms of days and in terms of cost one can obtain. So, it will be easier for future owners to decide rather to use older methods of construction or to switch on new methods. In comparison to traditional construction method by using 5D BIM the productivity of project can be increased. There are many positive impacts of 5D BIM that cannot be achieved through traditional planning methods. The most significant benefits of 5D BIM are found to be better visualization of construction process, better communication among project members and increased planning efficiency.

In addition to it, 5D BIM helps in achieving detailed and accurate work plans, quantity take-offs and cost estimates. 5D BIM enhances the efficiency of project schedule and also helps in increasing constructability and site safety. The research also conducted that 5D BIM can help the project manager in delivering a successful project. The project manager can make better decisions in the project process. With 5D BIM, a better depiction of reality is obtained, which makes it easier to see the consequences of their decisions. Hence a better basis of decisions is obtained through 5D BIM in comparison with traditional method and project manager can do a better job. In a nutshell, it is concluded that implementing 5D BIM can be a milestone development for construction firms and it can help mitigating the most common problems in the construction projects by controlling time and cost overruns with enhanced planning efficiency.

\section{Recommendation}

In future more dimensions of BIM like 6D BIM that tells the energy efficiency estimate of a building must be explored and research work should be done on it. In this way BIM can become a common construction tool of Pakistan industry. A company specialized in BIM must be devised to produce effective links between different companies and it should also provide training to the staff. In this way companies can be shifted towards 5D BIM. Seminars in universities and offices should be conducted to create awareness of benefits of 5D BIM in construction industry. In addition to it, software of 5D BIM should also be teach to civil and architecture students.

If the barriers in implementation of 5D BIM can be overcome, a large amount of BIM benefits can be extracted. This thing can bring drastic changes in construction industry of Pakistan. So, efforts should be done to overcome these barriers. Moreover, by application of 5D modeling on runtime projects of construction firm's actual data and information that determines the effectiveness of 5D modeling can be obtained. It will develop a broader perception of 5D BIM. Steps should be taken to increase the contribution of construction industry in economy of Pakistan that can only be possible if delays in schedule and cost over runs are controlled. For this, 5D BIM is a best choice that will help in boosting up our economy.

\section{References}

1. Shete, Kothawade (2016) An analysis of cost overruns and time. Overruns of Construction Projects in India, pp. 1-4

2. Eastman CM, Eastman C, Teicholz P, Sacks R, Liston K (2011) “BIM handbook: A guide to building information modelling for owners, managers, designers, engineers and contractors. John Wiley and Sons, Canada.

3. Yusuke Y, Tou T, Makoto K, Dai S (2014) BIM applications to large-scale complex building projects in Japan, pp. 1-14.

4. Marle, Vidal L (2016) Managing Complex, High Risk Projects, SpringerVerlag, London, UK, pp. 1-23.

5. Peter S (2016) Project cost management with 5D BIM. Procedia-Social and Behavioral Sciences 226:193-200. 
Creative Commons Attribution 4.0 International License

For possible submissions Click Here
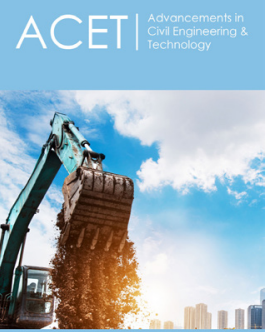

Advancements in Civil Engineering \& Technology

\section{Benefits of Publishing with us}

- High-level peer review and editorial services

- Freely accessible online immediately upon publication

- Authors retain the copyright to their work

- Licensing it under a Creative Commons license

- Visibility through different online platforms 